\title{
DESKRIPSI TINGKAT KEPUASAN MASYARAKAT TERHADAP PELAYANAN DI SATUAN PENYELENGGARA ADMINISTRASI SURAT IZIN MENGEMUDI KEPOLISIAN RESOR KOTA MANADO MENGGUNAKAN REGRESI LOGISTIK ORDINAL
}

\author{
Valdy Prasetyo Biri ${ }^{1)}$, Charles Mongi ${ }^{1)}$, Mans Mananohas ${ }^{1)}$ \\ ${ }^{1)}$ Program Studi Matematika, Fakultas Matematika dan Ilmu Pengetahuan Alam, \\ Universitas Sam Ratulangi Manado \\ e-mail : birivaldy@gmail.com; charlesmongi@unsrat.ac.id; mansmananohas@yahoo.com
}

\begin{abstract}
ABSTRAK
Pelayanan publik pada dasarnya berkaitan dengan aspek kehidupan yang sangat luas. Dalam kehidupan bernegara, pemerintah memiliki fungsi untuk memberikan berbagai pelayanan publik yang sebaik-baiknya untuk memenuhi kebutuhan masyarakat. Polri yang merupakan salah satu bagian pemerintah yang bertugas memberikan pelayanan kepada masyarakat terlebih khusus dalam hal pengurusan dan penerbitan surat izin mengemudi. Penelitian ini bertujuan untuk mendeskripsikan tingkat kepuasan masyarakat terhadap pelayanan di Satpas Polresta Manado dan menentukan variabel yang berpengaruh signifikan. Penelitian dilakukan di Satpas Polresta Manado dan beberapa tempat, seperti Yayasan Don Bosco Manado dan Universitas Sam Ratulangi Manado selama 5 bulan sejak Februari sampai Juli 2017. Data yang digunakan adalah data primer yang diperoleh melalui kuisioner yang dibagikan kepada responden. Dengan menggunakan regresi logistik ordinal diperoleh bahwa sebesar $86 \%$ masyarakat puas terhadap kinerja Polri. Variabel yang berpengaruh signifikan adalah cara pelayanan yang ramah dan sopan, informasi dalam mengisi formulir, serta fasilitas yang disediakan.
\end{abstract}

Kata kunci: regresi logistik ordinal, surat izin mengemudi, dan pelayanan publik

\section{DESCRIPTION OF SATISFACTION LEVEL OF THE COMMUNITY ON SERVICE AT ADMINISTRATION UNIT DRIVING LICENSE OF MANADO CITY POLICE USING ORDINAL LOGISTIC REGRESSION}

\begin{abstract}
Public service is basically related to a very broad aspect of life. In the life of the state, the government has a function to provide the best public services to meet the needs of the community. Polri which is one part of the government in charge of providing services to the public, especially in terms of the management and issuance of driver's license. This study aims to describe the level of public satisfaction of service in Satpas Polresta Manado and determine the variables that have significant effect. The research was conducted at Satpas Polresta Manado and several place such as Don Bosco Manado Foundation and Sam Ratulangi University Manado for 5 month from February to July 2017. The data used are primary data obtained through questionnaires distributed through respondents. By using ordinal logistic regression, $86 \%$ of the people are satisfied with the performance of the Polri. The variables that have a significant influence is the way the service friendly and polite, the information in filling out the form, as well as the facilities provided.
\end{abstract}

Keywords: ordinal logistic regression, driver's license, and public service

\section{PENDAHULUAN}

Pelayanan publik pada dasarnya berkaitan dengan aspek kehidupan yang sangat luas. Dalam kehidupan bernegara, pemerintah memiliki fungsi untuk memberikan berbagai pelayanan publik yang sebaik-baiknya untuk memenuhi kebutuhan masyarakat. Bersumber dari fungsi tersebut, maka tingkat kepuasan masyarakat terhadap 
pelayanan menjadi salah satu indikator atau tolak ukur dari keberhasilan penyelenggara sistem pemerintahan disuatu negara.

$$
\text { Menurut Setyaningsih (2009), }
$$

Kepolisian Republik Indonesia (Polri) yang dalam hal ini merupakan salah satu aparatur pemerintah yang bertugas untuk memberikan perlindungan, pengayoman dan pelayanan kepada masyarakat yang merupakan bagian dari fungsi pemerintahan negara, maka Satuan Lalu Lintas (Satlantas) sebagai bagian dari Polri yang bertugas memberikan pelayanan kepada masyarakat, khususnya dalam pengurusan dan penerbitan Surat Izin Mengemudi (SIM) di Kantor Satlantas berupaya meningkatkan kualitas pelayanan pada masyarakat guna memenuhi kebutuhan masyarakat dalam hal pelayanan publik.

Berdasarkan uraian diatas, maka peneliti tertarik menggunakan penerapan regresi logistik ordinal dalam mendeskripsikan tingkat kepuasan masyarakat terhadap pelayanan di Satuan Penyelenggara Administrasi Surat Izin Mengemudi Kepolisian Resor Kota Manado (Satpas Polresta Manado). Penelitian ini akan menggunakan data dari responden yang telah memiliki SIM dengan maksimal periode satu tahun berlaku sejak diterbitkan di Satpas Polresta Manado, dimana kalangan pelajar merupakan responden utama pada penelitian ini karena umumnya pemilik SIM baru berasal dari kalangan pelajar. Penelitian ini digunakan untuk menentukan model logistik, variabel-variabel yang signifikan terhadap model, dan menjadi acuan dalam pengambilan kesimpulan berdasarkan hasil analisis. Penelitian ini bertujuan untuk mendeskripsikan tingkat kepuasan masyarakat terhadap pelayanan di Satpas Polresta Manado, dan mendeskripsikan pengaruh variabel dalam model regresi logistik yang diperoleh.

\section{TINJAUAN PUSTAKA}

Surat Izin Mengemudi (SIM) merupakan tanda bukti bahwa pemegangnya telah memenuhi persyaratan-persyaratan yang dituntut perundang-undangan dengan melalui suatu ujian atau penelitian dan keterampilan mengemudi yang dilakukan oleh POLRI, sehingga SIM bagi masyarakat merupakan suatu tanda bukti kecakapan dan kemampuan untuk mengendarai dan mengemudikan kendaraan bermotor. (Hadiman dkk, 1986)

\section{Pelayanan Publik}

Pelayanan publik merupakan salah satu yang menjadi perhatian utama bagi masyarakat umum yang diselenggarakan oleh pemerintah dan penyedia jasa publik. Peningkatan kualitas pelayanan publik yang diselenggarakan oleh instansi pemerintahan pada saat ini menjadi sorotan bahkan menjadi tuntutan masyarakat. Persoalan yang sering dikritik masyarakat atau para penerima layanan adalah persepsi terhadap "kualitas" yang melekat pada seluruh aspek pelayanan.

Pada penelitian sebelumnya yang dilakukan oleh Baghi dan Goni (2012) tentang pelayanan terhadap publik dalam hal ini anggota masyarakat yang mengajukan permohonan SIM pada Satlantas Polresta Manado, dapat dilihat kinerja petugas kepolisian yang bertugas dalam pelayanan SIM tersebut. Pelayanan SIM yang dilaksanakan pada Satlantas Polresta Manado sudah tentu memiliki standar dan target yang akan dicapai dalam suatu periode tertentu. Berdasarkan penjelasan tersebut, maka pengertian kualitas pelayanan adalah terpenuhinya karakteristik suatu konsep pelayanan yang mencakup seluruh aspek pelayanan dan tolak ukur kualitas pelayanan itu adalah dapat memberi kepuasan kepada para pelanggan atau penerima layanan.

\section{Analisis Deskriptif}

Analisis data deskriptif merupakan cara mendeskripsikan atau menggambarkan data yang telah terkumpul sebagaimana adanya tanpa membuat kesimpulan yang berlaku untuk umum atau generalisasi. Ciriciri data deskriptif, yaitu penyajian data lebih ditekankan dalam bentuk tabel, grafik, dan ukuran-ukuran statistik, seperti persentase, rata-rata, varians, korelasi, dan angka indeks.

(Pramesti, 2014)

\section{Data dan Skala Pengukuran}

Data merupakan hasil pengukuran sebuah peubah (variabel). Agar data bisa dikerjakan dengan menggunakan statistika, maka semua data harus dinyatakan dalam 
bentuk angka atau bilangan, termasuk data kualitatif sehingga data tersebut perlu dikuantitatifkan melalui suatu proses pengukuran. Hasil pengukuran dibedakan atas empat macam skala, yaitu skala nominal, skala ordinal, skala interval, skala rasio. (Tiro, 2000)

\section{Validitas dan Reliabilitas}

Uji validitas digunakan untuk mengetahui sejauh mana suatu alat ukur mempunyai ketepatan dan kecermatan dalam melakukan fungsi ukurannya. Untuk mengukur validitas kuisioner yang diberikan kepada responden digunakan korelasi spearman rank (Hatidja, 2010) :

$$
\begin{gathered}
r_{s}=1-\frac{6 \sum d_{i}^{2}}{n\left(n^{2}-1\right)} \\
\sum d_{i}^{2}=\sum_{i=1}^{n}\left[R\left(X_{i}\right)-R\left(Y_{i}\right)\right]^{2}
\end{gathered}
$$$$
\text { Uji reliabilitas atau kehandalan }
$$

menunjukkan sejauh mana suatu pengukuran dapat memberikan hasil yang tidak berbeda bila dilakukan pengukuran kembali terhadap subjek yang sama. Suatu instrument reliabel bila nilai cronbach's alpha $>0,6$ dengan rumus sebagai berikut (Umar, 2008) :

$r_{i i}=\left(\frac{k}{k-1}\right)\left(1-\frac{\sum \delta_{b}^{2}}{\sum \delta_{t}^{2}}\right)$

\section{Analisis Regresi}

Analisis regresi adalah suatu metode sederhana untuk melakukan investigasi tentang hubungan fungsional diantara beberapa variabel. Pada model regresi, variabel dibedakan menjadi dua bagian, yaitu variabel respon (response) atau biasa juga disebut variabel bergantung (dependent variable) serta variabel penduga (predictor variable) atau disebut juga variabel bebas (independent variable). (Nawari, 2010)

\section{Regresi Logistik}

Menurut Sepang (2012), regresi logistik merupakan analisis yang digunakan untuk melihat hubungan antara variabel respon yang bersifat kategorik (kualitatif) dan variabel-variabel prediktor yang bersifat nominal atau ordinal (kualitatif) maupun interval atau rasio (kuantitatif).

Variabel prediktor yang bersifat kualitatif dapat digunakan variabel dummy (variabel boneka), sedangkan untuk variabel prediktor yang bersifat kuantitatif dapat dijabarkan secara langsung.

\section{Regresi Logistik Ordinal}

Menurut Albana (2013), regresi logistik ordinal adalah perluasan dari regresi logistik biner dimana regresi logistik ordinal merupakan salah satu metode statistika untuk menganalisis data dengan variabel respon merupakan skala ordinal yang terdiri dari tiga kategori atau lebih dan variabel prediktor merupakan covariate (jika menggunakan skala interval atau rasio) atau bisa merupakan faktor (jika menggunakan skala nominal atau ordinal).

\section{Model Regresi Logistik Ordinal}

Model regresi logistik adalah model regresi yang setiap peubah terikat atau responnya mensyaratkan berupa peubah kategorik. Model yang dapat dipakai untuk regresi logistik ordinal adalah model logit (model logistik).

$$
\begin{aligned}
& \operatorname{logit}\left(Y_{1}\right)=\ln \left(\frac{Y_{1}}{1-Y_{1}}\right)=\theta_{1}+\beta_{1} x_{1}+\cdots+\beta_{k} x_{k} \\
& \operatorname{logit}\left(Y_{2}\right)=\ln \left(\frac{Y_{2}}{1-Y_{2}}\right)=\theta_{2}+\beta_{1} x_{1}+\cdots+\beta_{k} x_{k}
\end{aligned}
$$

$\operatorname{Logit}\left(\mathrm{Y}_{\mathrm{j}-1}\right)=\ln \left(\frac{\mathrm{Y}_{\mathrm{j}-1}}{1-\mathrm{Y}_{\mathrm{j}-1}}\right)=\theta_{j-1}+\beta_{1} \mathrm{x}_{1}+\cdots+\beta_{\mathrm{k}} \mathrm{X}_{\mathrm{k}}$

\section{Uji Kebaikan Model}

Menurut Albana (2013), pengujian kebaikan model (goodness of fit) diakukan dengan menggunakan metode deviance. Uji kebaikan model digunakan untuk melihat kelayakan dari model yang diperoleh.

\section{Uji Kesignifikanan Parameter Secara Keseluruhan}

Menurut Albana (2013), metode umum yang digunakan untuk pengujian kesignifikanan peubah secara bersama-sama adalah metode uji perbandingan kemungkinan (ratio likelihood test). Uji ini membandingkan model lengkap (model dengan variabel prediktor) terhadap model yang hanya dengan konstanta (model tanpa variabel prediktor) untuk melihat apakah model yang hanya dengan konstanta secara signifikan lebih baik dari model lengkap.

\section{Uji Kesignifikanan Parameter Secara Parsial \\ Menurut Syah (2008), pengujian secara parsial dilakukan dengan menggunakan uji Wald untuk menguji}


parameter $\beta_{i}$ dengan cara merasiokan $\beta_{i}$ dugaan dengan kesalahan bakunya.

\section{Interpretasi Koefisien Model Regresi Logistik Ordinal}

Menurut Paputungan (2016), interpretasi koefisien untuk model regresi logistik ordinal dapat dilakukan dengan menggunakan nilai rasio odds-nya. Secara umum, rasio peluang (odds ratio) merupakan sekumpulan peluang yang dibagi oleh peluang lainnya. Jika model regresi logistik ordinal telah diuji dan hasil modelnya baik, serta signifikansinya nyata maka data tersebut dapat diinterpretasikan dengan menggunakan uji odds ratio yang dinotasikan dengan OR menggunakan persamaan :

$\mathrm{OR}=\frac{\text { peluang kejadian grup pertama }}{\text { peluang kejadian grup kedua }}$

\section{METODOLOGI PENELITIAN}

Penelitian ini menggunakan data primer yang dikumpulkan dan diolah sendiri oleh peneliti. Data tersebut berasal dari responden dengan menggunakan kuisioner sebagai alat pengumpulan data yang pokok

\section{Waktu dan Tempat Penelitian}

Pelaksanaan penelitian dilakukan sesuai dengan jadwal kegiatan yang direncanakan dan pengambilan data dilakukan di Satpas Polresta Manado dan beberapa tempat lainnya, seperti Yayasan Don Bosco Manado dan Universitas Sam Ratulangi Manado karena kaum pelajar merupakan responden utama dalam penelitian ini. Pelaksanaan penelitian dilakukan selama bulan februari sampai juli 2017 mulai dari penyusunan, pengambilan data, menganalisis data, dan mengintepretasi data.

\section{Populasi dan Sampel}

Populasi dalam penelitian ini adalah responden yang telah memperoleh SIM dengan maksimal periode satu tahun di Satpas Polresta Manado. Ukuran sampel yang diambil sebanyak 100 responden. Pengambilan sampel dilakukan dengan menggunakan teknik purposive sampling. Purposive sampling merupakan salah satu teknik pengambilan sampel dimana peneliti yang menentukan sendiri sampel yang akan diambil.

\section{Variabel Operasional}

Variabel penilaian masyarakat terhadap pelayanan merupakan variabel independen atau variabel bebas, dan tingkat kepuasan masyarakat secara keseluruhan merupakan variabel dependen atau variabel terikat. Terdapat 3 aspek yang akan menjadi acuan dalam menentukan variabel independen, yakni aspek pelayanan, aspek mekanisme dan informasi pengurusan, serta aspek sarana dan prasarana. Sedangkan untuk variabel dependen, terdapat 1 aspek yang menjadi acuan, yakni aspek penilaian secara keseluruhan. Variabel independen terdiri atas 8 variabel, diantaranya yakni 2 variabel aspek pelayanan, 5 variabel aspek mekanisme dan informasi pengurusan, dan 1 aspek sarana prasarana. Sedangkan untuk variabel dependen terdiri atas 1 variabel, yakni penilaian responden secara keseluruhan.

\section{Metode Analisis}

1. Penyusunan instrumen kuisioner yang digunakan sebagai pertanyaan merupakan aspek-aspek penelitian yang diperoleh melalui observasi yang dilakukan menggunakan tiga skala dengan rincian seperti pada Tabel 1 :

Tabel 1. Skala kepuasan

\begin{tabular}{|c|c|}
\hline Skala & Keterangan \\
\hline 0 & Tidak Puas \\
\hline 1 & Puas \\
\hline 2 & Sangat Puas \\
\hline
\end{tabular}

2. Melakukan pengambilan data melaui kuisioner sebagai alat pengumpulan data

3. Mendeskripsikan data yang diperoleh dengan analisis deskriptif

4. Melakukan uji validitas dan reliabilitas yang bertujuan untuk melihat kevaliditan suatu instrument dan kekonsistenannya.

5. Menyusun model regresi.

6. Melakukan uji kebaikan model dengan melihat nilai p_value pada metode deviance.

7. Melakukan uji hipotesis dengan menggunakan uji G dan uji W.

8. Melakukan interpretasi data dengan menggunakan odds ratio. 
9. Mengambil kesimpulan berdasarkan hasil analisis yang diperoleh.

\section{HASIL DAN PEMBAHASAN}

Berdasarkan data yang sudah terkumpul sebanyak 100 responden diperoleh beberapa deskripsi responden :

1. Umur Responden

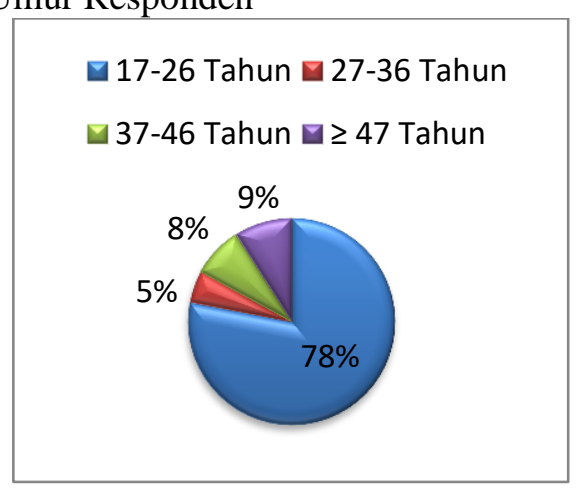

Gambar 1 Umur responden

2. Jenis Kelamin

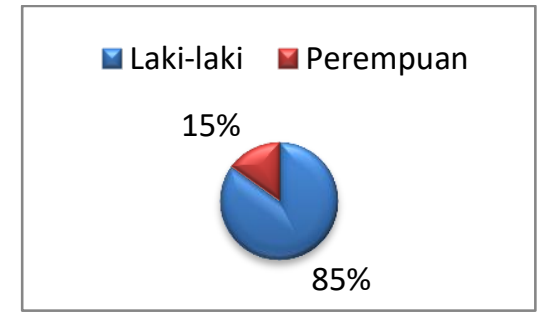

Gamber 2 Jenis Kelamin

3. Latar Belakang Pendidikan

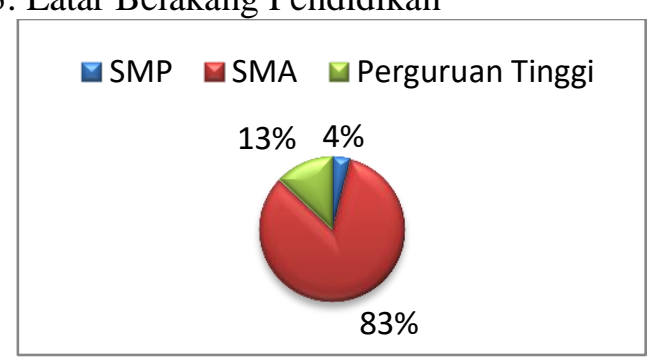

Gambar 3 Latar belakang pendidikan

\section{Profesi}

$\square$ Pelajar $\square$ Wiraswasta $\square$ PNS $\square$ Lainnya

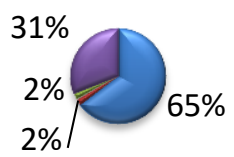

Gambar 4 Profesi

Uji Validitas dan Reliabilitas Kuisioner

Uji validitas menggunakan rumus korelasi spearman rank, dengan total responden yang akan diuji sebanyak 30 responden. Hipotesis yang akan diuji :

$\mathrm{H} 0=$ Tidak adanya korelasi antar pertanyaan kuisioner (rs_hitung $<$ rs_tabel)

$\mathrm{H} 1=$ Adanya korelasi antar pertanyaan kuisioner (rs_hitung $\geq$ rs_tabel)

Derajat kebebasan $(\mathrm{db})=\mathrm{n}=30$, dengan mengambil taraf nyata $(\alpha)=5 \%(0,05)$ maka diperoleh nilai rs_tabel sebesar 0,305. Berdasarkan hasil pengujian yang diperoleh, nilai $r$ hitung $\geq$ rs_tabel dengan nilai r_hitung masing-masing sebesar 0,622 untuk $\mathrm{X} 1$, sebesar 0,358 untuk X3, sebesar 0,535 untuk X4, sebesar 0,590 untuk X6, sebesar 0,562 untuk X7, sebesar 0,591 untuk X8, sehingga tolak $\mathrm{H} 0$ dan terima $\mathrm{H} 1$ dengan kesimpulan bahwa adanya korelasi antar pertanyaan pada kusioner sehinnga kuisioner pertanyaan dinyatakan valid. Dengan kata lain, variabel yang berskala ordinal pada kuisioner dinyatakan valid.

Uji reliabilitas menggunakan rumus cronbach's alpha, dengan total responden yang akan diuji sebanyak 30 responden. Hipotesis yang akan diuji :

$\mathrm{HO}=$ Kuisioner tidak dapat memberikan hasil yang konsisten sebagai alat ukur pengambilan data (cronbach's alpha $<0,6$ )

$\mathrm{H} 1$ = Kuisioner dapat memberikan hasil yang konsisten sebagai alat ukur pengambilan data (cronbach's alpha $>0,6$ )

Tabel 2. Hasil analisis reliabilitas

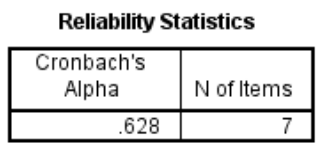

Berdasarkan hasil yang diperoleh nilai cronbachs alpha sebesar 0,628 (cronbach's alpha $>0,6$ ) maka tolak H0 dan terima $\mathrm{H} 1$ dengan kesimpulan bahwa kusioner dapat memberikan hasil yang konsisten sebagai alat ukur dalam pengambilan data sehingga kuisioner pertanyaan dinyatakan reliabel.

\section{Model Regresi Logistik}

Berdasarkan hasil yang diperoleh, maka model logit yang diperoleh adalah : Logit $(Y 1)=13,4217-5,47222 D 1 \_X 1$ 4,97202D2_X1-0,0005621X2 + 0,0159474D1_X3 - 4,72436D2_X3 4,73698D1_X4 - 6,74821D2_X4 0,212337X5 -2,98567D1_X6 0,617372D2_X6 - 0,594914D1_X7 - 
2,66493D2_X7 - 5,06185D1_X81,90483D2_X8

Logit $(Y 2)=27,2299-5,47222 D 1 \_X 1$ -

4,97202D2_X1 - 0,0005621X2 +

0,0159474D1_X3 - 4,72436D2_X3 -

4,73698D1_X4 - 6,74821D2_X4 -

0,212337X5 - 2,98567D1_X6-

0,617372D2_X6 - 0,594914D1_X7 -

2,66493D2_X7 - 5,06185D1_X8 -

1,90483D2_X8

\section{Uji Kebaikan Model}

Uji Kebaikan Model (Goodness of Fit) digunakan untuk melihat apakah model regresi logistik ordinal yang diperoleh layak untuk diguakan atau tidak. Hipotesis yang akan diuji adalah :

H0 : Model logit layak digunakan

H1 : Model logit tidak layak digunakan

Berdasarkan hasil yang diperoleh, diketahui nilai chi-square metode Deviance sebesar 45,7879 dengan derajat bebas sebesar 176 dengan kriteria pengujian tolak H0 jika P_value $<\alpha$. Pada Tabel 4, diperoleh

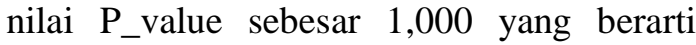
terima $\mathrm{HO}$ dengan kesimpulan bahwa model logit yang diperoleh layak digunakan.

Tabel 3 Hasil ujian kebaikan model

\begin{tabular}{|lrrr|}
\hline Method & Chi-Square & DF & P \\
Pearson & 89.6486 & 176 & 1.000 \\
Deviance & 45.7879 & 176 & 1.000 \\
\hline
\end{tabular}

\section{Uji Kesignifikanan Parameter Secara Keseluruhan}

Uji $G$ digunakan untuk menguji peranan variabel independen di dalam model secara bersama-sama. Hipotesis yang akan diuji adalah :

$\mathrm{H} 0: \beta \_1=\beta \_2=\cdots=\beta \_\mathrm{P}=0$

$\mathrm{H} 1$ : sekurang-kurangnya terdapat satu $\beta \mathrm{p} \neq$ $0(\mathrm{p}=1,2, \cdots, \mathrm{q})$

Jika $\mathrm{G}>\chi_{(\alpha, v)}^{2}$ maka tolak H0 dengan $\mathrm{v}$ merupakan banyaknya variabel prediktor, yaitu $d b=14$ sehingga kriteria pengujian dilakukan dengan mengambil taraf nyata $(\alpha)=5 \%(0,05)$ maka diperoleh nilai $\chi^{2}$ sebesar 23,684 .

Tabel 4 Uji parameter secara keseluruhan

Log-Likelihood $=-22.894$

Test that all slopes are zero:

$\mathrm{G}=54.326, \mathrm{DF}=14, \mathrm{P}-$ Value $=0.000$
Berdasarkan hasil pengujian seperti pada Tabel 4, hasil yang diperoleh terhadap nilai $\mathrm{G}$ adalah sebesar 54,326 $\left(\mathrm{G}>\chi^{2}{ }_{(\alpha, v)}\right)$ maka tolak $\mathrm{H} 0$ dan terima $\mathrm{H} 1$ dengan kesimpulan bahwa sekurang-kurangnya terdapat satu $\beta p \neq 0$, artinya bahwa sekurang-kurangnya terdapat satu variabel independen (variabel $\mathrm{X}$ ) yang mempengaruhi variabel dependen (variabel $\mathrm{Y})$.

\section{Uji Kesignifikanan Parameter Secara Parsial}

Uji w digunakan untuk menguji peranan variabel independen di dalam model secara parsial (masing-masing).Hipotesis yang akan diuji adalah :

$\mathrm{H} 0: \beta \mathrm{p}=0$

$\mathrm{H} 1: \beta \mathrm{p} \neq 0(\mathrm{p}=1,2, \cdots, \mathrm{q})$

Tabel 5 Hasil uji parameter secara parsial

\begin{tabular}{|c|c|c|c|}
\hline Predictor & Coef & SE Coef & P-value \\
\hline D1_X1 & $-5,47222$ & 2,34875 & 0,020 \\
D2_X1 & $-4,97202$ & 2,59192 & 0,055 \\
\hline X2 & $-0,0005621$ & 0,0132800 & 0,966 \\
\hline D1_X3 & 0,0159474 & 2,77209 & 0,995 \\
D2_X3 & $-4,72436$ & 3,17428 & 0,137 \\
\hline D1_X4 & $-4,73698$ & 2,07875 & 0,023 \\
D2_X4 & $-6,74821$ & 2,46037 & 0,006 \\
\hline X5 & $-0,212337$ & 0,194903 & 0,276 \\
\hline D1_X6 & $-2,98567$ & 1,81283 & 0,100 \\
D2_X6 & $-0,617372$ & 2,04104 & 0,762 \\
\hline D1_X7 & $-0,594914$ & 1,67335 & 0,722 \\
D2_X7 & $-2,66493$ & 1,90139 & 0,161 \\
\hline D1_X8 & $-5,06185$ & 1,98427 & 0,011 \\
D2_X8 & $-1,90483$ & 2,49181 & 0,445 \\
\hline
\end{tabular}

Jika $\mathrm{p}_{\text {value }}<\alpha$ maka tolak $\mathrm{H}_{0}$ sehingga kriteria pengujian dilakukan dengan mengambil taraf nyata $(\alpha)=5 \%(0,05)$. Berdasarkan hasil pengujian pada Tabel 5, hasil yang diperoleh yakni terdapat 4 (empat) variabel yang signifikan terhadap terhadap taraf nyata $(\alpha)=5 \%(0,05)$ atau $\left(\mathrm{p}_{\text {value }}<\alpha\right)$, yaitu variabel D1_X1, D1_X4, D2_X4, dan D1_X8.

Berdasarkan hasil yang diperoleh dari pengujian (uji D, uji G, uji W) untuk melihat variabel yang signifikan terhadap model, maka model logit yang diperoleh adalah :

$\operatorname{Logit}\left(Y_{1}\right)=13,4217-5,47222 \mathrm{D} 1 \_X 1$

$$
\begin{aligned}
& -4,73698 D 1 \_X 4 \\
& -6,74821 D 2 \_X 4 \\
& -5,06185 D 1 \_X 8
\end{aligned}
$$

$\operatorname{Logit}\left(Y_{2}\right)=27,2299-5,47222 D 1 \_X 1$

$$
\begin{aligned}
& -4,73698 D 1 \_X 4 \\
& -6,74821 D 2 \_X 4 \\
& -5,06185 D 1 \_X 8
\end{aligned}
$$




\section{Interpretasi Model}

Interpretasi model regresi logistik untuk data berskala ordinal menggunakan odds rasio dilakukan dengan menghitung perbandingan nilai peluang pada skala yang satu dengan skala lainnya seperti pada Tabel 6 , sebagai berikut :

Tabel 6 Hasil interpretasi model

\begin{tabular}{|c|c|c|c|}
\hline Skala & $\begin{array}{c}\text { Frekuensi } \\
\text { Variabel } \mathrm{Y}\end{array}$ & $\begin{array}{c}\text { Frekuensi Total } \\
\text { Variabel } \\
\left(\mathrm{X}_{1}, \mathrm{X}_{3}, \mathrm{X}_{4}, \mathrm{X}_{6}, \mathrm{X}_{7}, \mathrm{X}_{8}\right)\end{array}$ & Peluang \\
\hline $\begin{array}{c}\text { Tidak } \\
\text { Puas }\end{array}$ & 6 & 68 & 0,06 \\
\hline Puas & 86 & 462 & 0,86 \\
\hline $\begin{array}{c}\text { Sangat } \\
\text { Puas }\end{array}$ & 8 & 70 & 0,08 \\
\hline Total & 100 & 600 & 1,000 \\
\hline
\end{tabular}

1. odds $_{\text {puas }} /$ odds $_{\text {tidak puas }}=$

$$
\left(\frac{86}{462}\right) /_{\left(\frac{6}{68}\right)}=2,10
$$

Menyatakan bahwa kemungkinan jawaban puas 2,10 kali dibandingkan dengan jawaban tidak puas.

2.

$$
\begin{aligned}
& \text { odds }_{\text {sangat puas }} / \text { odds }_{\text {tidak puas }}= \\
& \left(\frac{8}{70}\right) /_{\left(\frac{6}{68}\right)}=1,29
\end{aligned}
$$

Menyatakan bahwa kemungkinan jawaban sangat puas 1,29 kali dibandingkan dengan jawaban tidak puas.

3.

$$
\begin{aligned}
& \text { odds }_{\text {sangat puas }} / \text { odds }_{\text {puas }}= \\
& \left(\frac{8}{70}\right) /\left(\frac{86}{462}\right)=0,61
\end{aligned}
$$

Menyatakan bahwa kemungkinan jawaban sangat puas 0,61 kali dibandingkan dengan jawaban puas.

\section{KESIMPULAN}

1. Tingkat kepuasan masyarakat terhadap pelayanan di Satpas Polresta Manado diperoleh nilai persentase untuk skala penilaian tidak puas sebesar 6\% (0.06), untuk skala penilaian puas sebesar $86 \%$ (0.86), dan untuk skala penilaian sangat puas sebesar $8 \%(0.08)$ yang berarti bahwa tingkat kepuasan masyarakat terhadap kinerja dari Polri yang dalam hal ini berkaitan dengan pelayanan kepada masyarakat dinilai memuaskan terlebih dalam hal pengurusan Surat Izin Mengemudi (SIM).

2. Variabel prediktor yang signifikan terhadap model atau terhadap variabel respon (tingkat penilaian secara keseluruhan terhadap pelayanan di Satpas Polresta Manado), yakni cara pelayanan yang ramah dan sopan, informasi dalam mengisi formulir, serta fasilitas yang disediakan.

\section{DAFTAR PUSTAKA}

Albana, M., A, Andriyati., dan F, Virgantari. 2013. Aplikasi Regresi Logistik Ordinal Untuk Menganalisa Tingkat Kepuasan Pengguna Jasa Terhadap Pelayanan di Stasiun Jakarta Kota [Skripsi]. FMIPA UNPAK, Bogor.

Baghi, Y.Y dan Goni, J.H. 2012. Efektivitas Kinerja Pelayanan Surat Izin Mengemudi Pada Satuan Lalu Lintas Kepolisian Resor Kota Manado. Jurnal Ilmu Administrasi 8(1) : 1 - 6

Hadiman, H., Soeratno, R., Harsono, S., Surbakti, R., Hutapea, U., dan Soeparmin. 1986. Menuju Tertib Lalu Lintas. Gadhessa Pura Mas, Jakarta.

Hatidja, D. 2010. Analisis Data Kategorik. Bahan Ajar. Manado : Materi Mata Kuliah Untuk Mahasiswa Semester VI Jurusan Matematika FMIPA UNSRAT, Manado.

Nawari. 2010. Analisis Regresi dengan MS Excel 2007 dan SPSS 17. PT Elex Media Komputindo, Jakarta.

Paputungan, N., Y, Langi., dan J, Prang. 2016. Analisis Regresi Logistik Ordinal Pada Tingkat Kepuasan Pengguna Jasa Terhadap Pelayanan di Bandara Internasional Sam Ratulangi Manado. Jurnal de Cartesian 5(2) : 73 $-79$ 
Pramesti, G. 2014. Kupas Tuntas Data Penelitian Dengan SPSS 22. Kompas Gramedia, Jakarta.

Sepang, F., H, Komalig., dan D, Hatidja. 2012. Penerapan Regresi Logistik Untuk Menentukan Faktor-Faktor Yang Mempengaruhi Pemilihan Jenis Alat Kontrasepsi Di Kecamatan Modayag Barat. Jurnal MIPA Unsrat Online 1(1) : 1-5

Setyaningsih, I.R. 2009. Kualitas Pelayanan di Kantor Urusan SIM Satlantas Polres Siragen. Surakarta [Skripsi]. FISIP USM, Surakarta.

Syah, S. 2008. Pemodelan Usia Menarche Dengan Regresi Logistik Ordinal dan Metode Chaid [Skripsi]. Program Studi Statistika IPB, Bogor.

Tiro, M.A. 2000. Analisis Regresi Dengan Data Kategori. Badan Penerbit Universitas Negeri Makassar, Makassar.

Umar, H. 2008. Metode Penelitian untuk Skripsi dan Tesis Edisi 2. Rajawali Pers, Jakarta. 